\title{
The Effects of Dental Status and Chewing Efficiency on the Oral-Health-Related Quality of Life of Nursing-Home Residents
}

This article was published in the following Dove Press journal: Clinical Interventions in Aging

\author{
Andreas Zenthöfer' \\ Judith Ehret $\mathbb{D}^{\prime}$ \\ Melania Zajac' \\ Samuel Kilian (D) ${ }^{2}$ \\ Peter Rammelsberg' \\ Anna-Luisa Klotz (D) \\ 'University of Heidelberg, Dental School, \\ Department of Prosthodontics, \\ Heidelberg 69120, Germany; ${ }^{2}$ University \\ of Heidelberg, Institute of Medical \\ Biometry and Informatics, Heidelberg \\ 69120 , Germany
}

Objective: The aim of this study was to evaluate the effects of dental status and chewing efficiency on the oral-health-related quality of life (OHRQoL) of nursing-home residents.

Materials and Methods: The study was conducted in nine nursing homes. All eligible participants were included, and general and medical data, information about nutritional status and their dental and prosthetic status were collected. Chewing efficiency was assessed by means of a two-colour mixing-ability test. The simple count version of the Geriatric Oral Health Assessment Index (SC-GOHAI) was used to evaluate participants' OHRQoL, and the Mini-Mental State Examination to classify the presence of cognitive impairment. Univariate and multivariate regression models were used to analyse data.

Results: The mean age of the participants was $82.1( \pm 9.8)$ years and most participants suffered from at least very mild cognitive impairment. OHRQoL for all participants $(n=$ $143)$ and denture wearers only $(n=105)$ was substantially associated with the type of prosthesis, the presence of natural teeth, the number of functional occluding pairs and dental and denture-related (if applicable) treatment needs. Furthermore, in both model's univariate analysis showed that chewing efficiency also affected OHRQoL. In contrast, multivariate analysis of all participants revealed that only a higher number of functional occluding pairs (C: $0.250 ; p<0.001)$, fewer dental treatment needs $(\mathrm{C}:-1.733 ; p=0.019)$ and a better nutritional status $(\mathrm{C}:-1.298 ; p=0.048)$ were relevant for better OHRQoL. For denture wearers, a higher number of functional occluding pairs (C: $0.192 ; p=0.011)$, a better denture condition $(\mathrm{C}:-2.194 ; p=0.003)$ and a higher body mass index (BMI) $(\mathrm{C}: 0.145 ; p=0.006)$ were the main variables associated with better OHRQoL among participants.

Conclusion: Good oral health and oral function, including chewing efficiency, are associated with a high OHRQoL of nursing-home residents. However, few dental treatment needs, well-fitting dentures without treatment needs and a high number of functional occluding pairs seem to be the principal variables for an acceptable OHRQoL of nursinghome residents.

Keywords: chewing efficiency, two-colour chewing-gum test, dental prostheses, OHRQoL, SC-GOHAI, BMI

\section{Introduction}

In the last decade, the oral health (e.g. periodontal health, caries experience, number of teeth) of seniors who live independently has seen improvement. ${ }^{1}$ However, the oral health of nursing-home residents - both with and without cognitive impairment and, in particular, dementia-has remained inadequate. ${ }^{2-4}$ Most nursing-home residents have dental or denture-related treatment needs and a reduced number of
Luisa Klotz

University of Heidelberg, Dental School, Department of Prosthodontics, INF 400,

Heidelberg 69120, Germany

Tel +496221568799

Fax +49 6221 56-537

Email anna-luisa.klotz@med.uni-

heidelberg.de 
teeth. ${ }^{5,6}$ These factors can affect the chewing efficiency of seniors and have also been associated with general health problems such as the aggravation of cardiovascular and infectious respiratory diseases. ${ }^{7,8}$ Health is not, however, only defined as an absence of disease, but also includes patients' subjective perceptions of their health (healthrelated quality of life). ${ }^{9}$ In this context, the effect of oralhealth-related quality of life (OHRQoL) on the subjective well-being and quality of life of seniors seems to be a significant one. ${ }^{10,11}$

Several studies have tried to discover which factors affect people's OHRQoL. Nonetheless, the thematic evidence available regarding nursing-home residents is still limited. In this context, the level of care needed is said to be relevant. ${ }^{12}$ Furthermore, dental variables such as the number of teeth, the rehabilitation of missing teeth using dental prostheses, and denture condition are described as affecting the OHRQoL of nursing-home residents. ${ }^{6,12-14}$ Study authors have speculated that this effect might be explained by reduced chewing efficiency. ${ }^{6,15}$ Chewing efficiency itself is affected by several variables including age, gender ${ }^{16}$ and salivary flow rate. ${ }^{17}$ Furthermore, toothrelated variables such as bite force, ${ }^{18}$ dental status, ${ }^{19,20}$ number of teeth, ${ }^{21}$ number of functional occluding pairs, $^{5,22}$ and occlusal characteristics ${ }^{23}$ have also been described as important. Furthermore, it has been determined that the type of prosthetic restoration also has an effect on chewing efficiency of adults and seniors. ${ }^{23,24}$

However, only limited information is available regarding the chewing efficiency of nursing-home residents. Furthermore, to the best of the authors' knowledge, no study has investigated the effect of chewing efficiency on the OHRQoL of nursing-home residents. This, however, would be of interest, as demographic changes lead to higher proportion of older people. Patient-centered outcomes of this group would help to improve healthcare decisions and are meaningful, valuable and helpful for the patient.

The aim of this study was therefore to evaluate the effects of dental status and chewing efficiency on the OHRQoL of nursing-home residents.

\section{Methods}

\section{Study Setting}

This study was approved by the local review board of the University of Heidelberg prior to its start (approval number S-420/2016). Nine long-term care facilities in Baden-
Württemberg and Hesse, two of the sixteen federal states of Germany, cooperated in the study. A dentist provided written and oral information about the study to all residents and their legal representatives. All residents or, if they were not sui legis, their legal representatives were subsequently asked to participate in the study and to give written and oral consent. To meet the inclusion criteria, residents had to be in long-term care and have no plans to move to another institution in the next year. There were no other inclusion criteria, and 150 residents (First nursing home: 31 residents; second nursing home: 30 residents; third nursing home: 26 residents; fourth nursing home: 21 residents; fifth nursing home: 19 residents; sixth nursing home: 15 nursing home; seventh nursing home: four residents; eighth nursing home: two residents; ninth nursing home: two residents) were included in the study.

\section{Sociodemographic Variables and Cognitive Impairment}

General information such as the age (in years), gender $(0=$ female, $1=$ male), height, weight and care level of patients was gathered from care documentation. This information was subsequently used to calculate body mass index (BMI). If the noted weight from the care documentation was older than a week, the seniors were weighed again on the day of the examination. Participants' nutritional status was also assessed subjectively by the dentists $(1=\operatorname{good}$ (normal body stature); 2 = reduced (to thin or to thick); $3=$ bad (very thin or very thick)). The level of care required was categorised into five grades according to the German care insurance grading system. Residents with no need of care were classified as grade 0 . Residents with minor care needs and those with considerable care needs were classified as grades 1 and 2, respectively. Grade 3 included residents with high care needs, whereas grade 4 included those with very high care needs. Residents with very high care needs and additional specialised nursing requirements were classified as grade 5 .

Participants' cognitive impairment was evaluated by use of the Mini-Mental State Examination (MMSE). ${ }^{25}$ The MMSE was used to evaluate the cognitive and motor skills of participants according to the way in which they solved 30 tasks. Tasks performed correctly were awarded one point, whereas failed exercises were awarded none. Scores could therefore range from 0 to 30 points. As recommended in several previous studies, participants attaining scores of fewer than 24 points were 
classified as having cognitive impairment. ${ }^{25-28}$ All examinations were performed by two dentists who had been trained at the Memory Clinic of the University of Heidelberg before the start of the study.

\section{Dental Variables}

Each participant underwent a comprehensive dental examination including an assessment of dental status, the presence $(0=$ "does not have own teeth", $1=$ "has own teeth") and number of teeth, the number of occluding pairs, the type and condition of the prosthesis worn and dental treatment needs (e.g. caries, periodontitis, fracture; $0=$ "no treatment needed", 1 = "treatment needed"). The number of functional occlusal pairs was defined as the number of static contacts (anterior and posterior teeth) between the maxillary and mandibular dentition. The condition of the prosthesis worn, if applicable, was evaluated using the category "dentures" of the Oral Health Assessment Tool (OHAT). ${ }^{29}$ The OHAT is a reliable and valid assessment instrument for oral health and can also be used by non-dental health professionals. The rating was dichotomous: $0=$ sufficient denture (no broken areas or teeth, dentures worn regularly); 1 = in need of repair (at least one broken area/tooth or dentures loose) ${ }^{29}$ For analytical purposes, the types of prosthesis worn were sorted into four categories: 1) natural teeth or fixed dental prosthesis (FDP); 2) removable dental prosthesis (RDP); 3) complete denture (CD); and 4) edentulous without replaced teeth (ENP). For the variable "denture status", each participant was classified according to the weaker restored jaw.

All dental examinations were performed by two dentists trained in the examination of older patients at the Department of Prosthodontics, University of Heidelberg, before the start of the study.

\section{Chewing Efficiency}

Chewing efficiency was evaluated by means of the twocolour mixing-ability test, which was described by Schimmel et al. in 2007. In this context, commercially available chewing gum (Hubba-Bubba Tape Gum ${ }^{\mathrm{TM}}$; The Wrigley Company Ltd, Plymouth, Devon, UK) in the colours blue (flavour: Sour Berry) and pink (flavour: Fancy Fruit) served as test food. The two types of chewing gum were prepared for the study by cutting strips $30 \mathrm{~mm}$ in length from each colour and sticking them together. The final dimensions of the strips were $30 \times 18 \times 3 \mathrm{~mm}^{30}$
The dentists instructed all participants, in the same way, asking them to chew the test food for 20 chewing cycles. In order to ensure that the exact number of chewing cycles is adhered to, the dentist gave the start signal to chew and counted while chewing. After 20 cycles, the dentist gave the participant a stop signal and the participant stopped chewing.

Afterwards, the gum samples were spat into a transparent plastic bag before a visual evaluation of mixing ability was performed by the dentists. The five categories were: 1 = chewing gum not mixed, impressions of cusps or folded once; 2 = large parts of chewing gum unmixed; 3 = bolus slightly mixed, but bits of unmixed original colour remain; 4 = bolus well mixed, but colour not uniform; $5=$ bolus perfectly mixed with uniform colour. ${ }^{30}$ The chewing gum samples were then flattened into wafers $1 \mathrm{~mm}$ thick and were scanned from both sides at a resolution of 1200 dots per inch using a flatbed scanner. The scanned chewing gum sampled were stored as.jpg files. The pictures were then imported into ViewGum software (dhal Software; Version 1.4.1.0, Kifissia, Greece) and analysed according to the protocol of Halazonetis et al (2013). ${ }^{31}$ Inadequate mixing was presented linearly and had a larger variance of hue than complete mixing.

\section{OHRQoL Assessment}

To assess OHRQoL, the German version of the GOHAI was used. ${ }^{32}$ The GOHAI requires participants to answer twelve questions related to pain and/or discomfort and physical and/or psychosocial function with regard to oral condition. In this study, the simple count score for GOHAI (SC-GOHAI) was used to identify extreme values of the GOHAI on a 3 -point scoring scale $(2=$ always, $1=$ sometimes and $0=$ never). Questions 3, 5, and 7 are inversely scaled $(0=$ always, $1=$ sometimes, $2=$ never $)$. The final SC-GOHAI score can therefore range from 0 to 24 points. Patients with a low GOHAI have poorer OHRQoL. ${ }^{32,33}$ This simple version of the GOHAI was used because many participants in this study sample had at least mild cognitive impairment. $^{32}$

In this study, the dentists read the questions slowly to the participants. A copy of the questionnaire was also handed to participants to enable them to read the questions themselves. If the participant gave invalid answers, or if the dentist believed that the participant was unable to differentiate between the answer categories, the question was repeated. Such events were documented, and the 
results from these participants were excluded from statistical analysis (discussed below).

\section{Statistical Analysis}

Statistical analysis was performed by use of the software R, version 3.4.2 (R Core Team; Auckland, New Zealand).

Means, standard deviations and frequencies were used to descriptively present the results. The association of the independent variables with the SC-GOHAI score was assessed by estimating a univariate linear regression model for each independent variable. For this, the ordinally scaled variables were dichotomised as follows: care level $(0=$ care level $0-2 ; 1=$ care level $3-5)$, nutritional status $(0=$ good, $1=$ reduced and poor $)$, total denture status ( $0=$ FDP and RDP; $1=\mathrm{CD}$ and ENP), subjective chewing efficiency $(0=$ categories $1-3 ; 1=$ categories 4-5). Multivariate linear regression was also conducted after a stepwise variable selection using the $p$-value to capture the most important factors affecting OHRQoL. All regression analyses were performed twice: once for all participants and once for residents wearing removable dentures only.

$P$-values lower than 0.05 were regarded as significant.

\section{Results}

\section{Characterisation of the Study Population}

Out of 150 seniors initially included, 143 (95.3\%) passed the SC-GOHAI and 146 (97.3\%) passed the two-colour chewing-gum test. The other participants were too ill to participate or refused participation.

Among the sample analysed $(\mathrm{n}=150)$, the mean age was $82.1( \pm 9.8)$ years, and $75 \%$ of participants were female. The mean MMSE was $19.2( \pm 8.4)$ points, and most participants suffered from at least very mild cognitive impairment. The mean GOHAI score for the sample was $20.7( \pm 3.4)$.

The mean number of remaining teeth was $10.1( \pm 9.8)$, and participants had a mean number of $7.7( \pm 4.7)$ functional occluding pairs. Out of all participants, 45 (30.0\%) had natural teeth or were fitted with a fixed dental prosthesis (FDP), 27 (18.0\%) wore a removable dental prosthesis (RDP) and 59 (39.3\%) wore complete dentures (CD). Nineteen seniors $(12.7 \%)$ were edentulous without replaced teeth in at least one jaw (ENP). Eighty per cent of the seniors had dental treatment needs, and the denture condition of most was inadequate $(66.7 \%)$. Chewing efficiency, evaluated by the variance of hue, was 0.6 ( \pm 0.25). For detailed results see Table 1 .

\section{Univariate Association with OHRQoL}

For all participants $(n=143)$, better OHRQoL was substantially associated with the type of prosthesis worn $(\mathrm{C}$ : $-1.672 ; p=0.003)$, the presence $(\mathrm{C}: 1.630 ; p=0.010)$ and a higher number of natural teeth $(\mathrm{C}: 0.091 ; p=0.002)$, a higher number of functional occluding pairs (C: 0289; $p<0.001)$ and fewer dental treatment needs (C: -2.367 ; $p=0.001)$. Furthermore, better chewing efficiency, as evaluated objectively (C: $-3.943 ; p<0.001)$ and subjectively (C: $1.553 ; p=0.020)$ by the chewing-gum test, had a substantial positive effect on OHRQoL $(n=139)$ (Figure 1 ). None of the other variables, including cognitive impairment, had an effect (Table 2). For denture wearers $(n=$ 105), a considerable association was detected between better OHRQoL and fewer dental $(\mathrm{C}:-2.461 ; p=0.002)$ and denture-related $(\mathrm{C}:-2.975 ; p<0.001)$ treatment needs as well as more functional occluding pairs (C: $0.285 ; p<$ 0.001). Furthermore, better chewing efficiency, as evaluated objectively $(\mathrm{C}:-4.103 ; p=0.004)$ and subjectively (C: $1.847 ; p=0.041$ ) by the chewing-gum test, positively affected the OHRQoL of denture wearers $(n=103)$. None of the other variables significantly affected the SC-GOHAI score $(p>0.05)$. Detailed results from these analyses are presented in Table 3.

\section{Multivariate Association with OHRQoL}

After selecting variables in the multivariate regression model for all participants, the following variables remained: number of functional occluding pairs (C: $0.250 ; p<0.001$, positive effect), dental treatment needed (C: $-1.773 ; p=0.010$, negative effect) and nutritional status (C: $-1.298 ; p=0.048$; worse nutritional status had a negative effect). For denture wearers, only a worse denture condition (C: $-2.194 ; p=0.003$ ), a higher number of functional occluding pairs (C: $0.192 ; p=0.011)$ and a higher BMI (C: $0.145 ; p=0.006)$ remained as contributors to a better OHRQoL among participants. Detailed results from these analyses are shown in Table 4.

\section{Discussion}

According to the findings of this study, good oral health and oral function (dental status, number of teeth and functional occluding pairs) and high chewing efficiency are associated with high OHRQoL. However, it seems the number of functional occluding pairs and dental and 
Table I Descriptive statistics for participant characteristics $(n=150)$

\begin{tabular}{|c|c|c|}
\hline & $\begin{array}{l}\text { Number of } \\
\text { Participants (\%) }\end{array}$ & $\begin{array}{l}\text { Mean } \\
\text { (SD) }\end{array}$ \\
\hline Age & - & $82.1(9.8)$ \\
\hline \multicolumn{3}{|l|}{ Gender } \\
\hline Female & $113(75.3 \%)$ & - \\
\hline Male & 37 (24.7\%) & - \\
\hline MMSE & - & $19.2(8.4)$ \\
\hline \multicolumn{3}{|l|}{ Care level } \\
\hline 0 & $4(2.7 \%)$ & - \\
\hline I & $6(4.0 \%)$ & - \\
\hline 2 & 45 (30.0\%) & - \\
\hline 3 & $46(30.7 \%)$ & - \\
\hline 4 & $42(28.0 \%)$ & - \\
\hline 5 & $7(4.7 \%)$ & - \\
\hline Body Mass Index & - & $27.7(6.6)$ \\
\hline \multicolumn{3}{|l|}{ Nutritional status } \\
\hline Good & $120(80.0 \%)$ & - \\
\hline Reduced & $26(17.3 \%)$ & - \\
\hline Bad & $4(2.7 \%)$ & - \\
\hline Number of teeth & - & $10.1(9.8)$ \\
\hline \multicolumn{3}{|l|}{ Natural teeth } \\
\hline Yes & 107 (71.3\%) & - \\
\hline No & $43(28.7 \%)$ & - \\
\hline \multicolumn{3}{|l|}{ Treatment needs } \\
\hline Yes & $120(80.0 \%)$ & - \\
\hline No & $30(20.0 \%)$ & - \\
\hline \multicolumn{3}{|l|}{ Pressure $(n=11)$} \\
\hline Yes & $23(20.7 \%)$ & - \\
\hline No & $88(79.3 \%)$ & - \\
\hline \multicolumn{3}{|l|}{ Total denture status } \\
\hline FDP/natural teeth & 45 (30.0\%) & - \\
\hline RPD & 27 (I8.0\%) & - \\
\hline$C D$ & 59 (39.3\%) & - \\
\hline ENP & 19 (12.7\%) & - \\
\hline $\begin{array}{l}\text { Number of functional } \\
\text { occluding pairs }\end{array}$ & - & $7.7(4.7)$ \\
\hline \multicolumn{3}{|l|}{ Denture condition $(n=I I I)$} \\
\hline Adequate & 37 (33.3\%) & - \\
\hline Inadequate & $74(66.7 \%)$ & - \\
\hline Chewing efficiency $(n=146)$ & - & $0.6(0.25)$ \\
\hline
\end{tabular}

Table I (Continued).

\begin{tabular}{|l|l|l|}
\hline & $\begin{array}{l}\text { Number of } \\
\text { Participants (\%) }\end{array}$ & $\begin{array}{l}\text { Mean } \\
\text { (SD) }\end{array}$ \\
\hline $\begin{array}{l}\text { Subjective evaluation of } \\
\text { chewing efficiency }(\boldsymbol{n}=\mathbf{1 4 6})\end{array}$ & & \\
$\mathrm{I}$ & $57(39.0 \%)$ & - \\
2 & $29(19.9 \%)$ & - \\
3 & $27(18.5 \%)$ & - \\
4 & $30(20.5 \%)$ & - \\
5 & $3(2.1 \%)$ & - \\
SC-GOHAI $(\boldsymbol{n}=\mathbf{1 4 3})$ & - & $20.7(3.4)$ \\
\hline
\end{tabular}

Abbreviations: FDP, fixed dental prosthesis; RPD, removable partial denture; CD, complete denture; ENP, edentulous without replaced teeth.

denture-related treatment needs (among denture wearers) have the most substantial effect on OHRQoL.

In this study, OHRQoL did not correlate with age, gender or cognitive impairment. This is in agreement with the literature. ${ }^{13,35}$ Furthermore, this study found no association between the level of care needed and OHRQoL, although it was associated with OHRQoL in a different study by Zenthöfer et al (2014). ${ }^{12}$ This difference might be explained by the recent change in January 2018 regarding how care levels are classified in Germany. These care levels are imprecise compared with the Barthel Index often used in the literature.

Compared with the OHRQoL score of the communitydwelling older people, ${ }^{32}$ the score of the sample in this study can be described as inadequate. This might be because the nursing-home sample had a low number of remaining teeth and a high number of treatment needs, both of which have been observed to affect the OHRQoL of nursing-home residents. ${ }^{6}$ In agreement with the findings of previous studies, ${ }^{6}$ the mean number of teeth correlated with OHRQoL. Because most participants in this study had dental treatment needs $(80.0 \%)$ or inadequate dentures (66.7\% of denture wearers), which can be associated with pain and discomfort, it is not surprising that these variables affected the OHRQoL score in univariate and multivariate analysis. Similar results were found in a previous nursinghome. ${ }^{6}$ Furthermore, these findings also support the hypothesis of Batista et al, who described an association between dental-related treatment needs and denture conditions among community-dwelling adults. ${ }^{36}$ 

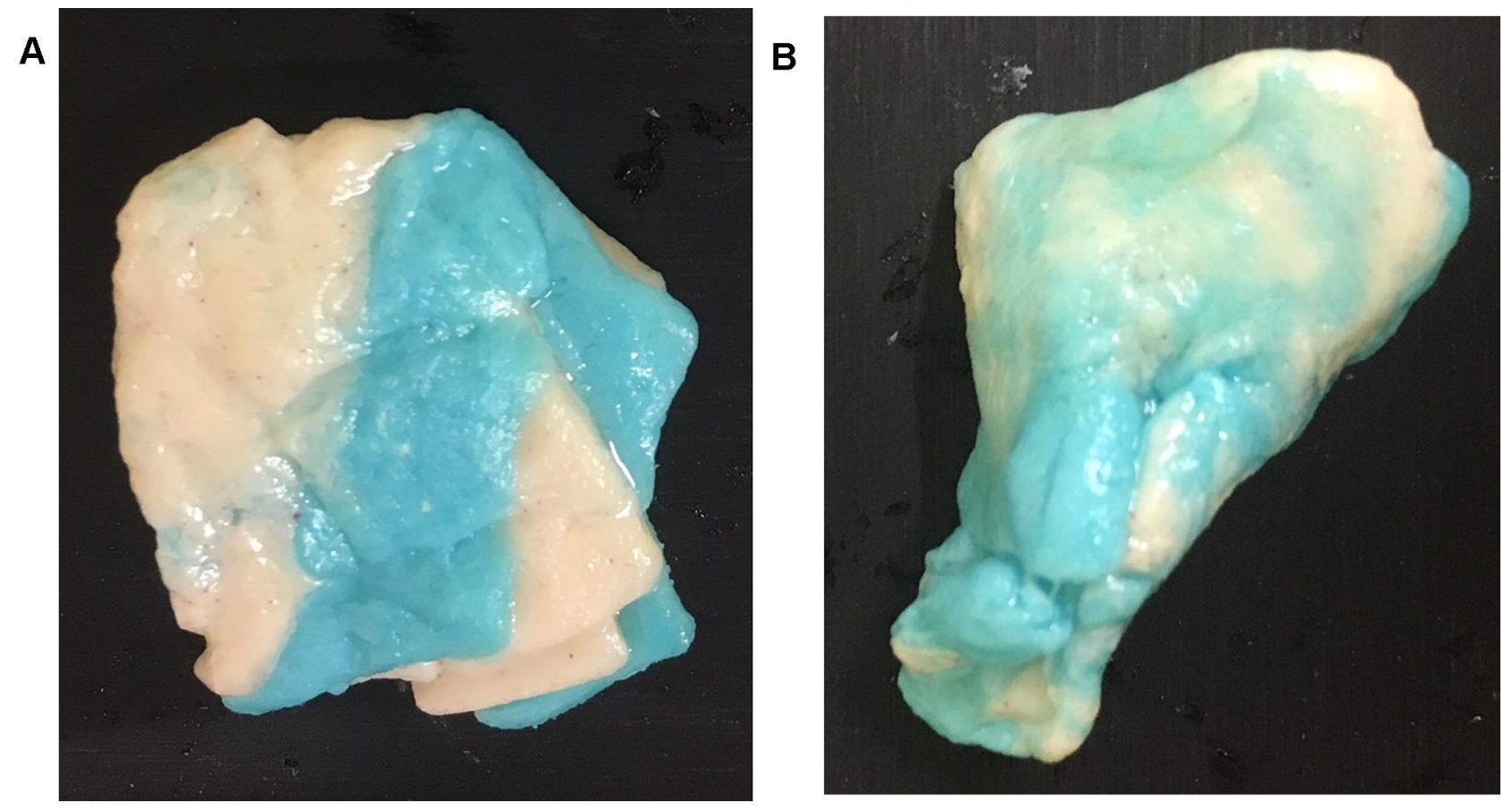

Figure I Examples of masticatory performance in the context of oral-health-related quality of life. (A) Senior with reduced oral-health-related quality of life. (B) Senior with acceptable quality of life.

In addition to the variables described, OHRQoL was also associated with the type of prosthetic restoration. In this context, FDP and RPD were associated with an increased OHRQoL. Several authors have found that prosthetic condition affects OHRQoL, which proves the importance of the dental and denture status of seniors. ${ }^{6,14,37}$ The authors speculated that this correlation might be explained by increased chewing efficiency. However, they did not investigate the chewing efficiency of nursing-home residents directly. In the literature, the chewing efficiency of participants with FDP (mean variance of hue of $0.38(0.1)$ ) was described as superior to that of participants with RPD and $\mathrm{CD}$ (mean variance of hue $0.69(0.19)){ }^{38-40}$ The findings of Schimmel et al and Wayler et al explain why chewing efficiency in this recent study (mean variance of hue $=0.06(0.25)$ ), evaluated subjectively and objectively by means of the two-colour chewing-gum tests, was lower than that of other studies investigating adults and the community-dwelling older people ${ }^{41,42}$ In this study sample, a high number of participants wore $\mathrm{CD}$ or were edentulous without replaced teeth in at least one jaw. Furthermore, the study sample analysed was advanced in age, which has also been associated with decreased chewing efficiency. ${ }^{43}$ Another potential influencing factor in our study is the high prevalence of cognitive impairment, which is also said to reduce chewing efficiency. ${ }^{44-46}$ However, the univariate analysis showed that chewing efficiency affected OHRQoL, which supports the hypothesis of Klotz et al (2017) and Tramini et al (2017). ${ }^{6,37}$ Because the subjective and objective chewing-efficiency tests both correlate with OHRQoL, use of the subjective evaluation in the nursing-home routine should be considered because it is short and uncomplicated. It is also worth noting that reduced chewing efficiency affects food selection, ${ }^{39}$ which might result in the need for soft and unhealthy food, in turn leading to a worse nutritional status and higher BMI. However, a higher BMI is associated with better OHRQoL. In this context, one should bear in mind that eating is a very important social event for nursing-home residents. ${ }^{47}$ For this reason, it seems logical that a higher BMI turned out to have an extremely significant effect on the OHRQoL of nursing-home residents with RDPs, CDs and those without dentures in this study.

Nevertheless, in multivariate analysis, a higher number of functional occluding pairs, fewer treatment needs and reduced nutritional status proved even more relevant for all participants. For denture wearers, in addition to a higher BMI, a higher number of functional occluding pairs and better denture condition proved most relevant for a better OHRQoL. These results indicate that good oral health, wellfitting dentures with no treatment needs and a high number of functional occluding pairs might provide subjectively good chewing function and therefore a better OHRQoL for nursing-home residents. A greater number of functional occluding pairs might improve confidence in chewing, even though 
Table 2 Univariate regression analysis with oral-health-related quality of life as the dependent variable and participant characteristics $(n=143)$

\begin{tabular}{|c|c|c|c|c|c|}
\hline Variable & C & 95\% CI LB & 95\% CI UB & $\mathbf{R}^{2}$ & $p$-value \\
\hline Age & 0.038 & -0.021 & 0.096 & 0.011 & 0.203 \\
\hline Gender & 0.365 & -0.942 & 1.672 & 0.002 & 0.582 \\
\hline MMSE & 0.051 & -0.024 & 0.127 & 0.013 & 0.183 \\
\hline Care level (dichotomised) & -0.577 & -1.741 & 0.586 & 0.007 & 0.328 \\
\hline Body Mass Index & 0.002 & -0.082 & 0.086 & 0.000 & 0.963 \\
\hline Nutritional status & -1.348 & -2.555 & 0.283 & 0.017 & 0.116 \\
\hline Number of teeth & 0.091 & 0.035 & 0.148 & 0.067 & 0.002 \\
\hline Natural teeth & 1.630 & 0.404 & 2.856 & 0.047 & 0.010 \\
\hline Treatment needs & -2.367 & -3.723 & -1.011 & 0.078 & 0.001 \\
\hline Total denture status (dichotomised) & -1.672 & -2.775 & $-0.57 \mid$ & 0.060 & 0.003 \\
\hline Number of functional occluding pairs & 0.289 & 0.176 & 0.402 & 0.154 & $<0.001$ \\
\hline $\begin{array}{l}\text { Chewing efficiency, subjective } \\
\text { (dichotomised, } n=139 \text { ) }\end{array}$ & 1.553 & 0.250 & 2.855 & 0.039 & 0.020 \\
\hline Chewing efficiency, objective $(n=139)$ & -3.943 & -6.081 & -1.805 & 0.088 & $<0.001$ \\
\hline
\end{tabular}

Note: Significant $p$-values are marked in bold.

Abbreviations: C, regression coefficient; $\mathrm{Cl}$, confidence interval; $\mathrm{LB}$, lower boundary; UB, upper boundary; $\mathrm{R}^{2}$, squared Pearson correlation.

it might take more time to chew. This might be why these variables were even more important than the chewingefficiency test and type of prosthetic restoration. However, it also should be kept in mind that the sample size was rather low. It might be that chewing efficiency would turn out to be relevant in a larger sample size.

These results highlight the importance of good dental and prosthetic conditions, which can be maintained by routine dental aftercare and periodic adjustment of dentures.

\section{Strength and Weaknesses of the Study}

It should be recognized that this study was an explorative pilot study. For this reason, a calculation of the sample size was not possible before the start of the study. Not all participants of the included nursing homes were participating in the study, this suggests caution in interpretation and generalization of the results. Participants were, perhaps, more interested in their health than non-responders. It is also conceivable that some of the subjects participated in the study because they had acute dental problems. However,

Table 3 Univariate regression analysis with oral-health-related quality of life as the dependent variable and participant characteristics for denture wearers only $(n=105)$

\begin{tabular}{|c|c|c|c|c|c|}
\hline Variable & C & 95\% CI LB & $95 \% \mathrm{Cl}$ UB & $\mathbf{R}^{2}$ & $p$-value \\
\hline Age & 0.028 & -0.041 & 0.098 & 0.006 & 0.417 \\
\hline Gender & -0.188 & -1.753 & 1.377 & 0.001 & 0.812 \\
\hline MMSE & 0.060 & -0.030 & 0.149 & 0.017 & 0.190 \\
\hline Care needed (dichotomised) & -0.829 & -2.181 & 0.524 & 0.014 & 0.227 \\
\hline Body Mass Index & 0.103 & -0.012 & 0.217 & 0.030 & 0.079 \\
\hline Nutritional status & -1.143 & -2.818 & 0.532 & 0.017 & 0.179 \\
\hline Teeth & 0.096 & -0.013 & 0.204 & 0.029 & 0.083 \\
\hline Natural teeth & 1.123 & -0.251 & 2.497 & 0.025 & 0.108 \\
\hline Treatment needs & -2.461 & -4.023 & -0.900 & 0.087 & 0.002 \\
\hline Pressure & -0.891 & -2.543 & 0.760 & 0.011 & 0.287 \\
\hline Total denture status (dichotomised) & -1.366 & -2.824 & 0.091 & 0.032 & 0.066 \\
\hline Number of functional occluding pairs & 0.285 & 0.151 & 0.419 & 0.148 & $<0.001$ \\
\hline Denture condition & -2.975 & -4.274 & -1.675 & 0.167 & $<0.001$ \\
\hline Subjective evaluation of chewing efficiency (dichotomised, $n=103$ ) & 1.847 & 0.073 & 3.622 & 0.041 & 0.041 \\
\hline Chewing efficiency $(n=103)$ & -4.103 & -6.848 & -1.359 & 0.080 & 0.004 \\
\hline
\end{tabular}

Note: Significant $p$-values are marked in bold.

Abbreviations: $\mathrm{C}$, regression coefficient; $\mathrm{Cl}$, confidence interval; LB, lower boundary; UB, upper boundary; $\mathrm{R}^{2}$, squared Pearson correlation. 
Table 4 Multivariate linear regression model after stepwise variable selection using the $p$-value with oral-health-related quality of life as the dependent variable

\begin{tabular}{|c|c|c|c|c|c|}
\hline Variables & C & 95\% CI LB & $95 \% \mathrm{CI}$ UB & Std. Error & $p$-value \\
\hline \multicolumn{6}{|l|}{ All participants $(n=143)$} \\
\hline Intercept & 20.382 & 18.707 & 22.056 & 0.847 & $<0.001$ \\
\hline Number of functional occluding pairs & 0.250 & 0.136 & 0.0 .365 & 0.058 & $<0.001$ \\
\hline Treatment needs & -1.733 & -3.050 & -0.413 & 0.667 & 0.010 \\
\hline Nutritional status & -1.298 & -2.586 & -0.010 & 0.652 & 0.048 \\
\hline \multicolumn{6}{|l|}{ Denture wearers only $(n=105)$} \\
\hline Intercept & 16.354 & 12.953 & 19.756 & 1.715 & $<0.001$ \\
\hline Denture condition & -2.194 & -3.647 & -0.741 & 0.732 & 0.003 \\
\hline Number of functional occluding pairs & 0.192 & 0.044 & 0.340 & 0.075 & 0.011 \\
\hline BMI & 0.145 & 0.043 & 0.247 & 0.051 & 0.006 \\
\hline
\end{tabular}

Note: Significant $p$-values are marked in bold.

Abbreviations: C, regression coefficient; Cl, confidence interval; LB, lower boundary; UB, upper boundary.

all potential residents of the participating nursing homes who gave informed consent were included in the study (irrespective of cognitive status and care needs).

It should also be remembered that self-assessments of oral health by elderly subjects with dementia was performed in this study; this may not be consistently accurate and may lead to underestimation of oral problems. OHRQoL was, however, assessed by use of the GOHAI, which has been reported to enable more successful and sensitive detection of oral problems among compromised elderly populations than use of the OHIP. In addition, the ability of the participants to give valid answers was confirmed by the interviewers in all cases. Each participant was asked the GOHAI questions and received the questionnaire to read, to reduce the possibility of bias. (As a consequence, results from 7 participants were excluded from statistical analysis.

A strength of the study is that the two dentists received comprehensive training and calibration before the start of the study.

\section{Conclusion}

OHRQoL among nursing-home residents is inadequate, and the need for dental and denture-related treatment is high. However, good oral health, well-fitting dentures with no treatment needs and a high number of functional occluding pairs are important for an acceptable OHRQoL of nursing-home residents. This underlines the importance of good dental and prosthetic conditions, which can be maintained by routine dental aftercare and the regular adjustment of dentures. In a geriatric setting, it may be meaningful to complete the dental examination with a chewing-efficiency test. Especially in compromised residents with dementia the chewing gum test could be an useful indicator for dental treatment need.

\section{Ethical Approval}

All procedures performed in studies involving human participants were in accordance with the ethical standards of the institutional and/or national research committee and with the 1964 Helsinki declaration and its later amendments or comparable ethical standards.

\section{Informed Consent}

Informed consent was obtained from each participant included in the study, or their legal representative.

\section{Acknowledgments}

We are grateful to all the participants in this study for their patience and cooperation.

We would also like to thank Hazel Davies, copy editor, for the English-language revision. ALK was supported by the GEROK Program of the University of Heidelberg.

\section{Disclosure}

The authors declare that they have no conflicts of interest.

\section{References}

1. Jordan AR, Micheelis W. Fünfte Deutsche Mundgesundheitsstudie (DMS V). Deutscher Ärzte-Verlag, Köln: Institut der Deutschen Zahnärzte (IDZ Matierialreihe Band 35); 2016.

2. Adam H, Preston AJ. The oral health of individuals with dementia in nursing homes. Gerodontology. 2006;23(2):99-105. 
3. Montal S, Tramini P, Triay JA, Valcarcel J. Oral hygiene and the need for treatment of the dependent institutionalised elderly. Gerodontology. 2006;23(2):67-72.

4. Zenthöfer A, Dieke R, Dieke A, Wege KC, Rammelsberg P, Hassel AJ. Improving oral hygiene in the long-term care of the elderly-a RCT. Community Dent Oral Epidemiol. 2013;41 (3):261-268.

5. Naka O, Anastassiadou V, Pissiotis A. Association between functional tooth units and chewing ability in older adults: a systematic review. Gerodontology. 2014;31(3):166-177.

6. Klotz AL, Hassel AJ, Schröder J, Rammelsberg P, Zenthöfer A. Oral health-related quality of life and prosthetic status of nursing home residents with or without dementia. Clin Interv Aging. 2017;12:659-665.

7. Juthani-Mehta M, De Rekeneire N, Allore H, et al. Modifiable risk factors for pneumonia requiring hospitalization of community-dwelling older adults: the Health, Aging, and Body Composition Study. J Am Geriatr Soc. 2013;61:1111-1118.

8. Scannapieco FA. Rethman MP: the relationship between periodontal diseases and respiratory diseases. Dent Today. 2003;22:79-83.

9. Callahan D. The WHO definition of 'health'. Stud Hastings Cent. 1973;1(3):77-88.

10. Hassel AJ, Danner D, Schmitt M, Nitschke I, Rammelsberg P, Wahl H-W. Oral health-related quality of life is linked with subjective well-being and depression in early old age. Clin Oral Investig. 2011;15(5):691-697. doi:10.1007/s00784-010-0437-3

11. Klotz A-L, Tauber B, Schubert A-L, et al. Oral health-related quality of life as a predictor of subjective well-being among older adults-A decade-long longitudinal cohort study. Community Dentistry and Oral Epidemiology. 2018;46(6):631-638. doi:10.1111/cdoe.12416

12. Zenthöfer A, Rammelsberg P, Cabrera T, Schröder J, Hassel AJ. Determinants of oral health-related quality of life of the institutionalized elderly. Psychogeriatrics. 2014;14(4):247-254. doi:10.1111/ psyg. 12077

13. John MT, Koepsell TD, Hujoel P, Miglioretti DL, LeResche L, Micheelis W. Demographic factors, denture status and oral health-related quality of life. Community Dentistry and Oral Epidemiology. 2004;32(2):125-132. doi:10.1111/j.03015661.2004.00144.x

14. Abud MC, Figueiredo MD. dos Santos MB, Consani RL, Marchini L. Correlation of prosthetic status with the GOHAI and TMD indices. Eur J Prosthodont Restor Dent. 2011;19(1):38-42.

15. Inukai M, John MT, Igarashi Y, Baba K. Association between perceived chewing ability and oral health-related quality of life in partially dentate patients. Health Qual Life Outcomes. 2010;8 (1):118. doi:10.1186/1477-7525-8-118

16. Akeel R, Nilner M, Nilner K. Masticatory efficiency in individuals with natural dentition. Swed Dent J. 1992;16:191-198.

17. Ikebe K, Matsuda K, Morii K, Furuya-Yoshinaka M, Nokubi T, Renner RP. Association of masticatory performance with age, posterior occlusal contacts, occlusal force, and salivary flow in older adults. Int J Prosthodont. 2006;19:475-481.

18. Fontijn-Tekamp FA, Slagter AP, Van Der Bilt A, et al. Biting and chewing in overdentures, full dentures, and natural dentitions. J Dent Res. 2000;79:1519-1524.

19. Van der Bilt A, Olthoff LW, Bosman F, Oosterhaven SP. The effect of missing postcanine teeth on chewing performance in man. Arch Oral Biol. 1993;38:423-429.

20. Fontijn-Tekamp FA, van der Bilt A, Abbink JH, Bosman F. Swallowing threshold and masticatory performance in dentate adults. Physiol Behav. 2004;83:431-436.

21. Elsig F, Schimmel M, Duvernay E, et al. Tooth loss, chewing efficiency and cognitive impairment in geriatric patients. Gerodontology. 2015;32(2):149-156.

22. Hatch JP, Shinkai RS, Sakai S. Determinants of masticatory performance in dentate adults. Arch Oral Biol. 2001;46(7):641-648.
23. Lujan-Climent M, Martinez-Gomis J, Palau S, Ayuso-Montero R, Salsench J, Peraire M. Influence of static and dynamic occlusal characteristics and muscle force on masticatory performance in dentate adults. Eur J Oral Sci. 2008;116(3):229-236.

24. Klotz AL, Ehret J, Zajac M, et al. The effects of prosthetic status and dementia on the chewing efficiency of seniors in nursing homes. J Oral Rehabil. 2020;47(3):377-385.

25. Folstein MF, Folstein SE, McHugh PR. "Mini-mental state". A practical method for grading the cognitive state of patients for the clinician. J Psychiatr Res. 1975;12:189-198.

26. Velayudhan L, Ryu SH, Raczek M, et al. Review of brief cognitive tests for patients with suspected dementia. Int Psychogeriatr. 2014;26:1247-1262.

27. Almeida OP. [Mini mental state examination and the diagnosis of dementia in Brazil]. Arq Neuropsiquiatr. 1998;56:605-612. [Article in Portuguese].

28. Tombaugh TN. McIntyre NJ: the mini-mental state examination: a comprehensive review. J Am Geriatr Soc. 1992;40:922-935.

29. Peter L. The oral health assessment tool - Validity and reliability. Aust Dent J. 2005;50(3):191-199.

30. Schimmel M, Christou P, Herrmann F, Müller F. A two-colour chewing gum test for masticatory efficiency: development of different assessment methods. J Oral Rehabil. 2007;34(9):671-678.

31. Halazonetis DJ, Schimmel M, Antonarakis GS, Christou P. Novel software for quantitative evaluation and graphical representation of masticatory efficiency. J Oral Rehabil. 2013;40(5):329-335.

32. Hassel AJ, Rolko C, Koke U, et al. A German version of the GOHAI. Community Dent Oral Epidemiol. 2008;36:34-42.

33. Atchison KA. Dolan TA: development of the Geriatric Oral Health Assessment Index. J Dent Educ. 1990;54:680-687.

34. Locker D, Matear D, Stephens M, Lawrence H, Payne B. Comparison of the GOHAI and OHIP-14 as measures of the oral health-related quality of life of the elderly. Community Dent Oral Epidemiol. 2001;29(5):373-381.

35. Ribeiro GR, Costa JL, Ambrosano GM, Garcia RC. Oral health of the elderly with Alzheimer's disease. Oral Surg Oral Med Oral Pathol Oral Radiol. 2012;114(3):338-343.

36. Batista MJ, Lawrence HP. de Sousa Mda L. Impact of tooth loss related to number and position on oral health quality of life among adults. Health Qual Life Outcomes. 2014;12:165.

37. Tramini P, Montal S, Valcarcel J. Tooth loss and associated factors in long-term institutionalised elderly patients. Gerodontology. 2007;24 (4): 196-203

38. Kaya MS, Güçlü B, Schimmel M, Akyüz S. Two-colour chewing gum mixing ability test for evaluating masticatory performance in children with mixed dentition: validity and reliability study. $J$ Oral Rehabil. 2017;44(11):827-834.

39. Schimmel M, Katsoulis J, Genton L, Muller F. Masticatory function and nutrition in old age. Swiss Dent J. 2015;125(4):449-454.

40. Wayler AH, Muench ME, Kapur KK, Chauncey HH. Masticatory performance and food acceptability in persons with removable partial dentures, full dentures and intact natural dentition. $J$ Gerontol. 1984;39(3):284-289.

41. Schimmel M, Christou P, Miyazaki H, Halazonetis D, Herrmann FR, Müller F. A novel colourimetric technique to assess chewing function using two-coloured specimens: validation and application. $J$ Dent. 2015;43(8):955-964.

42. Silva LC, Nogueira TE, Rios LF, Schimmel M, Leles CR. Reliability of a two-colour chewing gum test to assess masticatory performance in complete denture wearers. J Oral Rehabil. 2018;45(4):301-307.

43. Toro A, Buschang PH, Throckmorton G, Roldan S. Masticatory performance in children and adolescents with Class I and II malocclusions. Eur J Orthod. 2006;28:112-119.

44. Kim EK, Lee SK, Choi YH, et al. Relationship between chewing ability and cognitive impairment in the rural elderly. Arch Gerontol Geriatr. 2017;70:209-213. 
45. Tada A, Miura H. Association between mastication and cognitive status: A systematic review. Arch Gerontol Geriatr. 2017;70:44-53.

46. Weijenberg RA, Scherder EJ, Lobbezoo F. Mastication for the mindthe relationship between mastication and cognition in ageing and dementia. Neurosci Biobehav Rev. 2011;35(3):483-497.
47. Hassel AJ, Koke U, Schmitter M, Rammelsberg P. Factors associated with oral health-related quality of life in institutionalized elderly. Acta Odontol Scand. 2006;64(1):9-15.

\section{Publish your work in this journal}

Clinical Interventions in Aging is an international, peer-reviewed journal focusing on evidence-based reports on the value or lack thereof of treatments intended to prevent or delay the onset of maladaptive correlates of aging in human beings. This journal is indexed on PubMed Central, MedLine, CAS, Scopus and the Elsevier
Bibliographic databases. The manuscript management system is completely online and includes a very quick and fair peer-review system, which is all easy to use. Visit http://www.dovepress.com/ testimonials.php to read real quotes from published authors. 